\title{
Bonding structure and hydrogen content in silicon nitride thin films deposited by the electron cyclotron resonance plasma method
}

\author{
F.L. Martínez ${ }^{\mathrm{a} *}$, R. Ruiz-Merino ${ }^{\mathrm{a}}$, A. del Prado ${ }^{\mathrm{b}}$, E. San Andrés ${ }^{\mathrm{b}}$, I. Mártil ${ }^{\mathrm{b}}$, G. González-Díaz $^{\mathrm{b}}$, \\ C. Jeynes ${ }^{c}$, N.P. Barradas ${ }^{\mathrm{d}}$, L. Wang ${ }^{\mathrm{e}}$, H.S. Reehal ${ }^{\mathrm{e}}$ \\ ${ }^{a}$ Departamento de Electrónica y Tecnología de Computadoras, Universidad Politécnica de Cartagena, Campus Universitario Muralla del Mar, \\ 30202 Cartagena, Spain \\ ${ }^{\mathrm{b}}$ Departamento de Física Aplicada III, Universidad Complutense de Madrid, 28040 Madrid, Spain \\ ${ }^{\mathrm{c}}$ University of Surrey Ion Beam Centre, Guildford GU2 7XH, UK \\ ${ }^{\mathrm{d} I n s t i t u t o}$ Tecnológico e Nuclear, Estrada Nacional 10, 2686-953 Sacavém, Portugal \\ ${ }^{\mathrm{e}}$ Faculty of Engineering, Science, and Technology, South Bank University, 103 Borough Road, London SE1 OAA, UK
}

\begin{abstract}
The bonding structure and hydrogen content of amorphous hydrogenated silicon nitride (a-SiN $: \mathrm{H})$ thin films have been investigated by infrared spectroscopy and ion beam techniques. Electron cyclotron resonance plasma enhanced chemical vapor deposition was used to produce these films under different values of gas flow ratio, deposition temperature, and microwave power. The amount of bonded hydrogen was calculated from the $\mathrm{N}-\mathrm{H}$ and $\mathrm{Si}-\mathrm{H}$ infrared absorption bands. An increase of the $\mathrm{SiH}_{4}$ partial pressure during deposition was found to have the same effect on the $\mathrm{H}$ content as an increase of the substrate temperature: both cause a decrease of the $\mathrm{N}-\mathrm{H}$ bond density and an increase in the number of Si-H bonds. This is explained by a competitive process in the formation of $\mathrm{N}-\mathrm{H}$ and $\mathrm{Si}-\mathrm{H}$ bonds during the growth of the film, whereby $\mathrm{Si}-\mathrm{H}$ bonds are favored at the expense of $\mathrm{N}-\mathrm{H}$ bonds when either the $\mathrm{SiH}_{4}$ flow or the substrate temperature are increased. Such tendency to chemical order is compared with previous results in which the same behavior was induced by thermal annealing or ion beam bombardment. (C) 2003 Elsevier B.V. All rights reserved.
\end{abstract}

PACS: 61.43.Er; 68.55.Ln; 78.30.Ly; 82.30.Hk

Keywords: Silicon nitride; Hydrogen; Bonding energy; Network bond reactions

\section{Introduction}

The need for high- $k$ dielectrics in the microelectronics industry has led to intensive research in a number of materials with potential applications as gate dielectrics in complementary metal-oxide-semiconductor (CMOS) transistors [1]. This is motivated by the continuous downscaling of the channel length into the $100 \mathrm{~nm}$ range, which requires a reduction of gate oxide thickness to $1.5-2.0 \mathrm{~nm}$ in order to maintain the transconductance of the device. In this ultrathin range Boron penetration from the $\mathrm{p}^{+}$-polysilicon gate and hot-electron effects degrade the lifetime of the device. Many ultrathin $(<3$ $\mathrm{nm}$ ) silicon dioxide films are now nitrided in order to

\footnotetext{
*Corresponding author. Tel.: +34-968-326465; fax: +34-968326400.

E-mail address: Felix.Martinez@upct.es (F.L. Martínez).
}

reduce those effects and prolong the lifetime of the device.

However, as the thickness of the nitrided silicon dioxide is further decreased, gate leakage (direct and Fowler-Nordheim tunneling currents) through the dielectric layer becomes a major concern. Higher-permittivity dielectric films, which could be made thicker with capacitances equivalent to those of the ultrathin oxides, are being sought to reduce the leakage currents.

Silicon nitride and/or oxynitride alloys are the preferred candidates to reach the equivalent oxide thickness between 1 and $1.5 \mathrm{~nm}$ that will be needed for $70 \mathrm{~nm}$ channel lengths, while scaling down to the $50 \mathrm{~nm}$ node will require alternative dielectrics of even higher values of $k$, such as $\mathrm{Ta}_{2} \mathrm{O}_{5}$ or $\mathrm{TiO}_{2}$.

But the applications of silicon nitride are not limited to CMOS gate dielectrics. Silicon nitride has been widely used as passivation and protection layer due to 
its low permeation to alkali and small ions [2]. In solar cells and photodiodes those properties are combined with the choice of refractive index and thickness to form an antireflection coating. Also, in thin film transistors (TFTs) silicon nitride is the dielectric of choice for the gate structure of these devices due to its better interface properties with amorphous or polycrystalline silicon $[3,4]$.

The aim of this paper is to contribute to the understanding of the structural properties of silicon nitride and the role played by the hydrogen atoms which are incorporated during the growth of the film. The amount of hydrogen depends on the method of deposition and the precursor gases, and because of this hydrogen the chemical composition of silicon nitride is better described as $\operatorname{SiN}_{x}: \mathrm{H}$. In the present work we will study the evolution of the hydrogen content with deposition conditions and compare it with the evolution resulting from thermal treatments and ion beam bombardment. From this analysis we will be able to propose a network bond reaction driven by the tendency to maximum bonding energy.

\section{Experimental procedure}

The $\mathrm{SiN}_{x}: \mathrm{H}$ films which are the subject of this study were obtained using an electron cyclotron resonance plasma enhanced chemical vapor deposition (ECRPECVD) system (Plasma Technology AMR) equipped with a load-locked vacuum chamber and pumped by a Leybold turbomolecular pump capable of reaching base pressures of $10^{-7}$ Torr [5]. Electronic grade nitrogen and silane were used as precursor gases. Nitrogen was introduced into the ECR chamber as the plasma gas, while silane entered into the deposition chamber through a gas dispersal ring.

The substrates were p-type silicon wafers suitable for infrared spectroscopy. They were subjected to standard RCA cleaning steps ending with a diluted HF: $\mathrm{H}_{2} \mathrm{O}$ (1:10) solution to remove superficial oxide. After a final deionized water rinse and drying with nitrogen they were introduced into the deposition chamber. Different sample series were deposited with a constant $\mathrm{N}_{2}$ gas flow of $50 \mathrm{sccm}$ and $\mathrm{SiH}_{4}$ flows ranging between 2 and $5 \mathrm{sccm}$, so that the $\mathrm{N}_{2} / \mathrm{SiH}_{4}$ gas flow ratio (referred as $R$ in the following) had values between 10 and 25 . We concentrate our study on three deposition temperatures $\left(T_{\mathrm{d}}\right): 230,310$ and $470{ }^{\circ} \mathrm{C}$. Microwave power $(P)$ was $200 \mathrm{~W}$ for these three series, but an additional set of samples varying $P$ between 300 and $500 \mathrm{~W}$ was also prepared. In this latter case $R$ was kept constant at 12.5 $\left(\mathrm{SiH}_{4}\right.$ flow of $\left.4 \mathrm{sccm}\right)$ and $T_{\mathrm{d}}$ was $470{ }^{\circ} \mathrm{C}$.

All samples were analyzed by Fourier transform infrared spectroscopy (FTIR) with a Nicolet Magna-IR 750 spectrometer. The spectra were taken in transmission mode at normal incidence. After subtracting the spec-

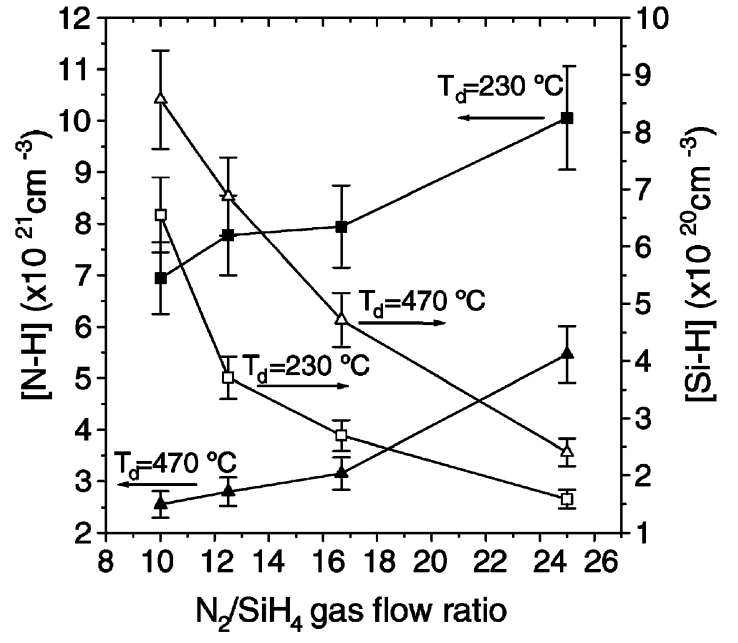

Fig. 1. N-H and $\mathrm{Si}-\mathrm{H}$ bond densities versus precursor gases flow ratio. Closed symbols correspond to $\mathrm{N}-\mathrm{H}$ bond densities, while open symbols refer to $\mathrm{Si}-\mathrm{H}$ concentrations. Two different sample series are considered corresponding to deposition temperatures of $230{ }^{\circ} \mathrm{C}$ (squares) and $470{ }^{\circ} \mathrm{C}$ (triangles). Lines are guides for the eye. Error bars are an estimate of $10 \%$ uncertainty in the calculation of FTIR band areas.

trum of the silicon substrate, the three well known absorption bands of $\mathrm{SiN}_{x}: \mathrm{H}$ at $3340 \mathrm{~cm}^{-1}(\mathrm{~N}-\mathrm{H}$ stretching), $2155 \mathrm{~cm}^{-1}$ ( $\mathrm{Si}-\mathrm{H}$ stretching) and $830-890 \mathrm{~cm}^{-1}$ ( $\mathrm{Si}-\mathrm{N}$ stretching) were studied. From the $\mathrm{Si}-\mathrm{H}$ and $\mathrm{N}-\mathrm{H}$ stretching bands the concentrations of bonded hydrogen $([\mathrm{Si}-\mathrm{H}]$ and $[\mathrm{N}-\mathrm{H}])$ were determined using the wellknown calibration factors originally obtained by Lanford and Rand [6] and confirmed by some of us in a recent work using a different calibration technique [7].

The samples were also subjected to composition measurements with ion beam techniques. By Rutherford back-scattering spectroscopy (RBS) we determined the nitrogen to silicon ratio, while the total hydrogen content could be measured separately by elastic recoil detection analysis (ERDA). In both cases we used $1.5 \mathrm{MeV}$ $\mathrm{He}^{+}$ions: in RBS at a scattering angle of $160^{\circ}$ and in the case of ERDA at $26^{\circ}$ [8].

\section{Results}

Fig. 1 shows the density of bonded hydrogen calculated from the infrared absorption bands of the $\mathrm{Si}-\mathrm{H}$ and $\mathrm{N}-\mathrm{H}$ bonds. We plot in this graph the results corresponding to the series deposited at the substrate temperatures of $230{ }^{\circ} \mathrm{C}$ and $470{ }^{\circ} \mathrm{C}$. The trends are clear and indicate that the density of $\mathrm{N}-\mathrm{H}$ bonds increases as the $\mathrm{N}_{2}$ to $\mathrm{SiH}_{4}$ gas flow ratio is increased (i.e. as the $\mathrm{SiH}_{4}$ flow decreases), while the density of $\mathrm{Si}-\mathrm{H}$ bonds follows the opposite trend. Higher values of deposition temperature have the same effect as increasing the $\mathrm{SiH}_{4}$ flow: they produce a decrease in the number of $\mathrm{N}-\mathrm{H}$ bonds and an increase in $[\mathrm{Si}-\mathrm{H}]$. 


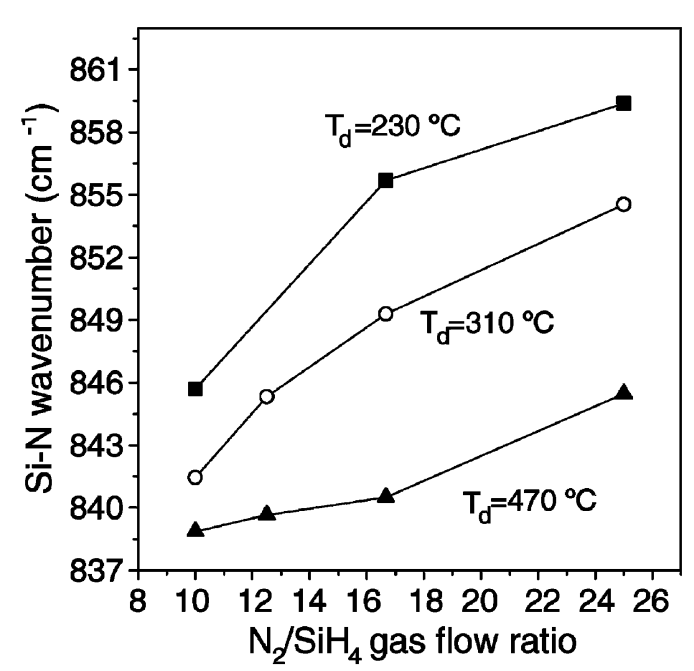

Fig. 2. Wavenumber at absorption peak of the $\mathrm{Si}-\mathrm{N}$ stretching band versus precursor gases flow ratio. The data correspond to three sample series deposited with three different substrate temperatures: 230,310 and $470{ }^{\circ} \mathrm{C}$. Lines are a guide for the eye.

As to the $\mathrm{Si}-\mathrm{N}$ absorption band, its peak position (wavenumber at maximum absorption) is related to the $\mathrm{N}-\mathrm{H}$ concentration due to the higher electronegativity of hydrogen with respect to silicon. The vibration frequency of a chemical bond is directly related to the electronegativity of the nearest neighbors due to the attraction that they exercise on the electronic cloud of the bond. This produces a shortening of the bond length, which in its turn causes an increase in the oscillation frequency. In Fig. 2 we have done a plot of the $\mathrm{Si}-\mathrm{N}$ wavenumber as a function of gas flow ratio for the three different temperatures. There is a clear correlation with the $\mathrm{N}-\mathrm{H}$ bond concentration of Fig. 1.

In order to emphasize the relation between the $\mathrm{Si}-\mathrm{N}$ wavenumber and the $\mathrm{N}-\mathrm{H}$ bond concentration we have compiled in Fig. 3 all the data corresponding to the different series that have been studied. Three of these series have the $\mathrm{N}_{2}$ to $\mathrm{SiH}_{4}$ flow ratio as deposition variable and correspond to three different substrate temperatures: 230,310 and $470{ }^{\circ} \mathrm{C}$, while the fourth series has the microwave power as the variable and correspond to a deposition temperature of $470{ }^{\circ} \mathrm{C}$. The effect of increasing the microwave power on $[\mathrm{N}-\mathrm{H}]$ and [Si-H] is analogous to increasing the $\mathrm{N}_{2}$ to $\mathrm{SiH}_{4}$ gas flow ratio, because higher values of $P$ mean a higher proportion of nitrogen species activated by the plasma (this has been corroborated by Langmuir probe measurements [8]).

\section{Discussion}

The opposite trends followed by the $\mathrm{N}-\mathrm{H}$ and $\mathrm{Si}-\mathrm{H}$ bond densities have been observed in previous works by some of us as a function of annealing temperature
[9] and ion beam bombardment [7]. In those works the infrared absorption bands were studied for different sample series subjected to rapid thermal annealing (RTA) treatments at temperatures ranging between 300 and $1050{ }^{\circ} \mathrm{C}$ and irradiated with heavy ions at fluences between $10^{11}$ and $10^{14} \mathrm{~cm}^{-2}$. Those results were explained by network bond reactions taking place at different temperature ranges or activated by the ion irradiation. Such chemical reactions are driven by the tendency for maximum bonding energy (stronger bonds are favored at the expense of weaker bonds). Therefore the energy balance of those reactions is exothermic, although they need an activation energy that was provided by the thermal annealing process or by the ion beam.

In the present study we observe that a similar behavior takes place during the growth process as a function of two different variables: $R$ (precursor gas flow ratio) and $T_{\mathrm{d}}$ (substrate temperature). Increasing the $\mathrm{SiH}_{4}$ flow during the deposition (i.e. decreasing $R$ ) has the same effect as increasing the substrate temperature: both favor $\mathrm{Si}-\mathrm{H}$ bonds at the expense of $\mathrm{N}-\mathrm{H}$ bonds. It seems as if the $\mathrm{SiH}_{4}$ flow and the temperature were acting as limiting factors for the formation of $\mathrm{Si}-\mathrm{H}$ bonds. Once any of these variables is increased, the $\mathrm{Si}-\mathrm{H}$ concentration increases at the expense of the number of $\mathrm{N}-\mathrm{H}$ bonds.

The chemical reaction that explains this behavior is illustrated in Fig. 4 and it is given by the following equation:

$\mathrm{Si}-\mathrm{Si}+\mathrm{N}-\mathrm{H} \rightarrow \mathrm{Si}-\mathrm{H}+\mathrm{Si}-\mathrm{N}$

This is a well-known [10] network bond process favored by the tendency to chemical order, whereby the

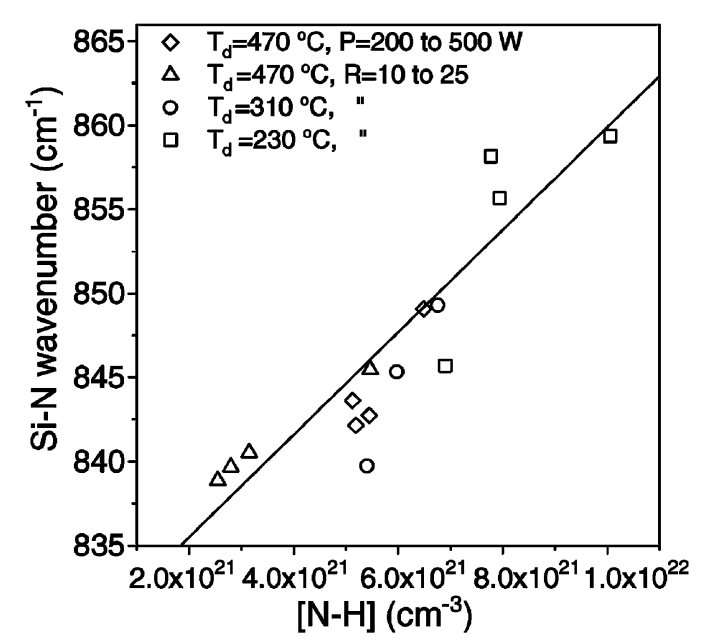

Fig. 3. Correlation between the $\mathrm{Si}-\mathrm{N}$ peak wavenumber and the $\mathrm{N}-\mathrm{H}$ bond density. This graph compiles the data from the three series deposited at different substrate temperatures and an additional series in which the microwave power used to ignite the plasma was varied. 

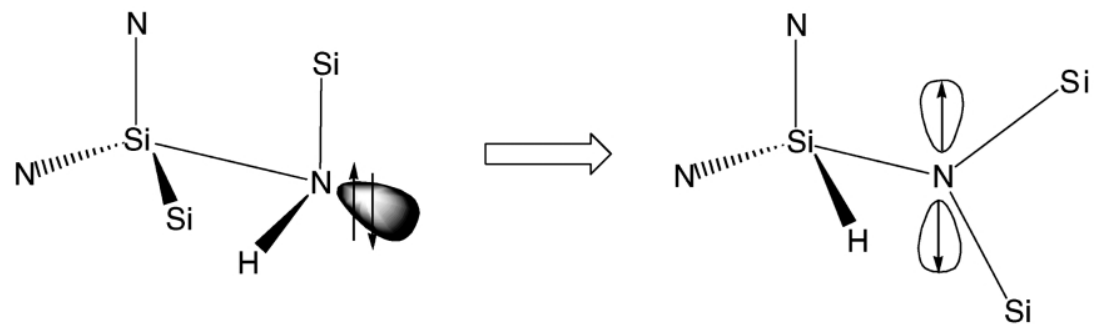

Fig. 4. Schematic illustration of the trend for chemical order, whereby the $\mathrm{Si}-\mathrm{H}$ and $\mathrm{Si}-\mathrm{N}$ bonds are favored at the expense of $\mathrm{Si}-\mathrm{Si}$ and $\mathrm{N}-\mathrm{H}$ ones as predicted by the free-energy model of Yin and Smith. In the present work this behavior is observed as the $\mathrm{SiH}_{4}$ gas flow or the substrate temperature are increased.

formation of $\mathrm{Si}-\mathrm{H}$ and $\mathrm{Si}-\mathrm{N}$ bonds is favored at the expense of $\mathrm{Si}-\mathrm{Si}$ and $\mathrm{N}-\mathrm{H}$ bonds. Taking into account nominal bond energies [11,12] this process is exothermic, with a favorable energy balance of $0.25 \mathrm{eV}$.

The bond scheme drawn in Fig. 4 might illustrate how reaction (1) proceeds in a near stoichiometric environment such as that of the samples being analyzed here. An interesting point of discussion is the nitrogen atom electronic orbital hybridization. In the initial situation it is bonded to two silicon atoms and one hydrogen atom, and the most stable configuration is the $\mathrm{sp}^{3}$ tetrahedral hybridization $[13,14]$. In the final situation the nitrogen will be bonded to three silicon atoms as a consequence of the bond interchange reaction. In this case, the interaction between the doubly occupied $p_{z}$ non-bonding orbital perpendicular to the bond plane and the internal $d$ orbitals of the three silicon atoms makes the $\mathrm{sp}^{2}$ planar hybridization of the nitrogen atom highly stable $[13,15]$. Such interaction receives the name of $\mathrm{p}_{\pi}-d_{\pi}$ and it is known to occur only in the $\mathrm{N}-\mathrm{Si}_{3}$ and $\mathrm{N}-\mathrm{Ge}_{3}$ bonding, giving them a characteristic planar geometry in contrast with the more usual tetrahedral hybridization of nitrogen.

The chemical reaction given by equation 1 does not produce any change in composition, only in chemical configuration. Nevertheless, the results of the measurements of atomic concentration by RBS-ERDA indicate a slight decrease of the $\mathrm{N} / \mathrm{Si}$ ratio (denoted as $x$ in the chemical formula) and of the $\mathrm{H}$ atomic percent (at.\%) when increasing the $\mathrm{SiH}_{4}$ flow (i.e. when decreasing $R$ ). For the series deposited at $310{ }^{\circ} \mathrm{C}, x$ decreases from 1.6 to 1.2 as the $\mathrm{SiH}_{4}$ flow increases from 2 to $5 \mathrm{sccm}$, while the atomic percent of hydrogen decreases from 24.7 to 18.4 at.\% in that same interval. For the other two series the trends are similar [8]. This is mainly due to an increase in the number of $\mathrm{Si}$ atoms, being the number of $\mathrm{N}$ atoms roughly constant, and it is consistent with a decrease of the $\mathrm{N}-\mathrm{H}$ bond concentration that is more significant than the corresponding increase of the Si-H bond density (Fig. 1).

\section{Conclusions}

The formation of $\mathrm{Si}-\mathrm{H}$ and $\mathrm{N}-\mathrm{H}$ bonds appear as a competitive process during the growth of $\mathrm{SiN}_{x}: \mathrm{H}$ films. When the $\mathrm{SiH}_{4}$ flow or the substrate temperature are increased $\mathrm{Si}-\mathrm{H}$ bonds are favored at the expense of $\mathrm{N}-\mathrm{H}$ bonds. The behavior of the $\mathrm{N}-\mathrm{H}$ bond density is corroborated by changes in the $\mathrm{Si}-\mathrm{N}$ infrared band peak wavenumber, which shifts to lower values when the $\mathrm{N}-\mathrm{H}$ concentration decreases.

The substitution of $\mathrm{N}-\mathrm{H}$ bonds with $\mathrm{Si}-\mathrm{H}$ bonds is driven by the tendency for chemical order or maximum bonding energy, whereby stronger bonds are favored at the expense of weaker bonds according to a well-known network bond reaction originally proposed by Yin and Smith [10]. The same behavior has been observed in previous experiments where $\mathrm{SiN}_{x}: \mathrm{H}$ samples were irradiated with high energy beams of heavy ions [7] or subjected to rapid thermal annealing treatments [9].

\section{Acknowledgments}

This work was partially supported by the Ministry of Science and Technology (Spain) under contract TIC2001/1253.

\section{References}

[1] D.A. Buchanan, IBM J. Res. Dev. 43 (1999) 245.

[2] I.A. Ross, Proc. IEEE 86 (1998) 7.

[3] T.P. Ma, IEEE Trans. Electron Devices 45 (1998) 680.

[4] S.S. He, M.J. Williams, D.J. Stephens, G. Lucovsky, J. NonCryst. Solids 164-166 (1993) 731.

[5] S. Summers, H.S. Reehal, G.H. Shirkoochi, J. Phys. D 34 (2001) 2782.

[6] W.A. Lanford, M.J. Rand, J. Appl. Phys. 49 (1978) 2473.

[7] W. Bohne, W. Fuhs, J. Röhrich, B. Selle, G. González-Díaz, I. Mártil, F.L. Martínez, A. del Prado, Surf. Interface Anal. 30 (2000) 534.

[8] L. Wang, H.S. Reehal, F.L. Martínez, E. San Andrés, A. del Prado, Semicond. Sci. Technol. 18 (2003) 633. 
[9] F.L. Martínez, A. del Prado, I. Mártil, G. González-Díaz, W. Bohne, W. Fuhs, J. Röhrich, B. Selle, I. Sieber, Phys. Rev. B 63 (2001) 245320.

[10] Z. Yin, F.W. Smith, Phys. Rev. B 43 (1991) 4507.

[11] I.N. Levine, Physical Chemistry, McGraw-Hill, New York, 1988.

[12] F.W. Smith, Z. Yin, J. Non-Cryst. Solids 137-138 (1991) 871.
[13] G. Lucovsky, Z. Zing, D.R. Lee, J. Vac. Sci. Technol. B 14 (1996) 2832.

[14] Z. Jing, G. Lucovsky, J.L. Whitten, J. Vac. Sci. Technol. B 13 (1995) 1613

[15] N.N. Greenwood, A. Earnshaw, Chemistry of the Elements, Pergamon, Oxford, 1984. 